\title{
EKSPLORASI ORIENTASI BUDAYA INDONESIA DALAM WACANA JURNALISTIK BERBAHASA INDONESIA
}

\author{
Nur Fajar Arief \\ FKIP Universitas Islam Malang \\ e-mail: nfarief999@yahoo.com
}

\begin{abstract}
Abstrak
Penelitian ini bertujuan mendeskripsikan orientasi budaya masyarakat Indonesia dalam aspek mikro wacana jurnalistik berita. Jenis penelitian adalah analisis wacana interpretatif. Analisis data dilakukan dengan dua model, yakni analisis wacana deskriptif dan analisis wacana kritis. Hasil penelitian sebagai berikut. Pertama, orientasi budaya masyarakat Indonesia mengarah pada tipologi budaya kolektif. Kedua, aktivitas masyarakat Indonesia dalam berbagai fakta sosial menunjukkan kesesuaian dengan indikator-indikator posisi kesadaran budaya kolektif. Ketiga, orientasi budaya Indonesia yang ditemukan meliputi orientasi pada: (a) peristiwa yang bersifat longgar dan tanpa mempedulikan waktu, (b) pemikiran holistik, (c) hal non-kritis dengan selalu menerima hidup apa adanya, (d) hubungan manusia dengan ciri mempertahankan relasi, (e) status, kedudukan, dan peran sosial tertentu daripada prestasi dan kemampuan, dan (f) kerentanan yang disembunyikan dengan tidak mengungkapkan suatu kesalahan, kegagalan, dan kelemahan secara terbuka dan publikatif.
\end{abstract}

Kata kunci: orientasi budaya, wacana jurnalistik, budaya kolektif

\section{AN EXPLORATION OF THE INDONESIAN CULTURAL ORIENTATION IN INDONESIAN JOURNALISTIC DISCOURSES}

\begin{abstract}
This study aims to describe the Indonesian society's cultural orientation in the microaspects of news journalistic discourses. This was an interpretive discourse analysis study. The data were analyzed using two models, namely descriptive discourse analysis and critical discourse analysis. The findings are as follows. First, the Indonesian society's cultural orientation leads to the typology of collective culture. Second, the Indonesian society's activities in a variety of social facts show relevance to the indicators of the position of collective culture awareness. Third, the Indonesian cultural orientations include those to: (a)loose and time-free events, (b) holistic thinking, (c) non-critical matters by accepting life as it is, (d) the human relationship with a characteristic of maintaining relation, (e) a certain status, position, and social role more than to achievement and capability, and (f) hidden vulnerability by not revealing a mistake, failure, and weakness openly and publicly.
\end{abstract}

Keywords: cultural orientation, journalistic discourses, collective culture

\section{PENDAHULUAN}

Sebagai sarana komunikasi, bahasa berfungsi sebagai wadah menyampaikan informasi dan pengalaman baik yang bersifat kultural maupun individual. Pengalaman kultural ini meliputi berbagai pengetahuan dan peraturan tentang berpikir, bertindak, dan berperilaku seba- gaimana sistem budaya, sistem sosial, dan artefak. Pengalaman individual meliputi ide/gagasan, perasaan, dan tindakan individu dalam berbagai bidang hidup dan kehidupan. Kedua pengalaman tersebut merupakan realisasi pikiran kognitif suatu masyarakat tentang bagaimana menyusun perangkat-perangkat budaya, 
bagaimana menafsirkan gejala alam sekitarnya, bagaimana mengklasifikasikan masing-masing fenomena tersebut, bagaimana memberikan makna terhadap hasil klasifikasi, serta bagaimana mengkomunikasikannya melalui bahasa. Dengan demikian, kompleksitas dua pengalaman di atas senantiasa berbanding lurus dengan kompleksitas bahasa yang difungsikan sebagai alat untuk berkomunikasi.

Ditinjau dari segi proses pemerolehan dan pembelajaran suatu budaya, bahasa mempunyai peran instrumental dalam rangka mengenal, memahami, dan melakukan wujud budaya dengan berbagai unsur dan subunsurnya. Meskipun secara kodrati manusia dapat belajar melalui pengamatan dan peniruan, tetapi kompleksitas pengalaman masa lampau, masa kini, dan masa yang akan datang tetap membutuhkan sistem lambang yang menjamin terkomunikasikannya seluruh pengalaman tersebut secara utuh (kontekstual). Melalui bahasa setiap anggota suatu budaya mengkomunikasikan ide/ gagasan, pengalaman, dan kepercayaan kultural masa lampau, masa sekarang, serta meneruskannya kepada generasi berikutnya.

Bahasa melambangkan segala sesuatu yang dirasakan, dipikirkan, dan disampaikan antara individu/masyarakat yang satu dan individu/masyarakat yang lain. Proses sosialisasi ini hanya dimungkinkan karena keberadaan bahasa. Pada tingkatan filosofis dapat dinyatakan bahwa terdapat hubungan yang koordinatif maupun subordinatif antara budaya dan bahasa, sedangkan pada tingkatan teknis tergambar bahwa aktivitas berbahasa dapat merefleksikan jati diri masyarakat penuturnya. Pernyataan inilah yang mendasari pemahaman bahwa bahasa merupakan alat pengikat sosial yang paling kuat, berfungsi sebagai (1) alat komunikasi luar (antarindividu atau antarmasyarakat), (2) alat komunikasi dalam (diri sendiri atau masyarakat), dan (3) alat pembentuk pandangan hidup atau keduniaan suatu bangsa.

Kajian bahasa dan pikiran melalui penelitian yang dilakukan Edward Sapir \& Benjamin Lee Worf (1921) terhadap beberapa bahasa dan bangsa melahirkan hipotesis "unggulan" yakni "fashion of speaking influences habitual behavior and thought". Hipotesis ini melahirkan diktum-diktum pernyataan, antara lain (1) bahasa mencerminkan perilaku, (2) bahasa merupakan lambang sempurna dari pengalaman, dan (3) manusia yang mempunyai bahasa berbeda hidup dalam world of reality yang berbeda-beda, sehingga daya tangkap dan cara berpikirnya pun juga berbeda. Meskipun hipotesis ini mengalami pro dan kontra-versi lemah yang lebih banyak diterima - keberadaannya justru menstimulasi euforia kajian budaya dan bahasa dalam berbagai interdisipliner.

Kajian filsafat bahasa menegaskan inklusifitas bahasa dan budaya dalam bentuk pandangan bahwa seluk beluk kehidupan manusia dapat diketahui melalui bahasa.Bahasa merepresentasikan hakikat pengetahuan konseptual manusianya. Sejalan dengan hal ini, Martinich (2000) menyatakan "Language is a reflection of our thought about reality... Language is social phenomenon which is part of the natural history of human beings; a spere of human action... and wherein people respond by thought and action to the sound or marks which they observe to have been so produced".

Berbagai penelitian tentang inklusifitas di atas juga dilakukan oleh para ahli interdisipliner antara linguistik dan sosiologi, filsafat, anthropologi, serta psikologi (lihat Clark \& Clark, 1977; Chaika, 1982; Gumperz, 1968; Nababan, 1984; Giglioli, 1985; Wertsch, 1985; Kartomihardjo, 1981; Hayakawa \& Hayakawa, 1990; Purwo, 1992; Valdes, 1995; dan Summary of SIETAR Houston Monthly Meeting, 20002004). Beberapa di antaranya. Geertz (1973) menelaah tatakrama sosial orang Jawa melalui leksikon, struktur kalimat, 
dan tingkat tutur bahasa Jawa. James Fox (1986) menelaah pandangan hidup dunia dan religius orang Roti melalui leksikonleksikon, gaya bahasa, dan ragam bahasa Roti. Gumperz (1968) menelaah perbedaan cara menyusun argumen yang berterima dari dua kelompok yang berlatar belakang budaya berbeda. Kesemua kajian menegaskan bahasa dapat menjadi "kunci utama" mengetahui dan memahami kebudayaan penuturnya.

Secara subjektif ketertarikan peneliti untuk mengkaji fenomena tersebut dilandasi beberapa rasional empirik, pertama, kajian yang secara spesifik menelaah cerminan budaya Indonesia dalam teks/ wacana tulis dengan mengelaborasikan kerangka berpikir teoretis dan analitis secara lintasdisipliner belum banyak berkembang. Kajian-kajian yang pernah ada relatif menggunakan kerangka berpikir teoretis dan analitis secara interdisipliner. Penelitian yang pernah dilakukan tersebut di antaranya Noerhadi (1992) tentang posisi kata-kata diektik bahasa Indonesia, Wahab (1998) tentang inklusifitas budaya dalam retorika Indonesia, Suparti dkk. (1992) tentang leksikon dan taksonomi emosi lintas-budaya, Gunarwan (1992) tentang kesantunan direktif di dalam bahasa Indonesia, DuFon dan Wahab (1994) tentang perbandingan strategi kesantunan berbahasa antara bahasa Inggris, Jawa, dan Indonesia, Eriyanto (2001) tentang analisis ideologi dalam wacana berita, dan Santoso (2002) tentang penggunaan bahasa Indonesia dalam wacana politik. Hal ini mendorong daya dan upaya peneliti untuk melakukan pengembangan kajian dengan kerangka elaboratif tersebut melalui "pintu masuk" wacana jurnalistik berita berbahasa Indonesia.

Antonio Gramsci (Van Dijk, 2003) melalui teori hegemoni berpandangan bahwa keberadaan dan profil kehidupan manusia dapat dibentuk dan direkonstruksi melalui bahasa. Nilai, norma, dan perilaku manusia dapat dikendalikan (doktrinisasi) melalui bahasa. Bahasa dapat dijadikan "pintu masuk dan keluar" untuk mengetahui dan memahami keberadaan dan kehidupan manusianya. Jika pernyataan ini dianalogikan, maka (1) manusia Indonesia dalam batas-batas tertentu berada dalam kendali bahasa Indonesia, (2) profil manusia Indonesia merupakan hasil konstruksi sosial melalui bahasa Indonesia, dan (3) proses rekonstruksi melalui "pintu masuk" bahasa Indonesia akan menghasilkan "keluaran" pemahaman dan pengetahuan tentang budaya manusia Indonesia. Dengan demikian penelitian ini semakin esensial dilaksanakan dalam rangka mendeskripsikan budaya masyarakat Indonesia melalui kerangka berpikir teoretis dan analisis yang lebih komprehensif.

Kedua, wacana jurnalistik berita dalam berbagai media massa cetak mempunyai fungsi yang strategis tidak hanya sekedar menyampaikan informasi, tetapi juga mendidik, menghibur, mempengaruhi, dan bahkan membentuk tatanan makro dalam berbagai segi. Kompilasi fakta yang ditransformasikan melalui aspek makro, aspek superstruktur, dan aspek mikro tertentu pada akhirnya berubah bentuk menjadi opini umum (public opinion). PAK2I (2004) mencantumkan hal ini sebagai salah satu pokok pikiran tentang pers Indonesia sebagai berikut.

"Jati diri Pers Indonesia bukan hanya berbentuk wajah semata yang menafikan nilai-nilai moralitas dan nasionalisme sebagai bangsa, akan tetapi jati diri pers Indonesia justru harus menampakkan diri sebagai dinamisator dan mediator bagi pemberdayaan masyarakat dalam menjaga moralitas serta tata nilai sesuai karakter bangsa itu sendiri. Di sinilah masyarakat pers harus bisa menjadi pilar/ garda depan bangsa yang menyuarakan semangat seluruh elemen masyarakat dalam melestarikan dan membangkitkan jiwa nasionalisme dan patriotisme bangsanya". 
Ketiga, secara keilmuan esensi pentingnya penelitian ini didasari oleh beberapa rasional teoritik. Berdasarkan kajian ideasional dan aksiologis dalam tiga bidang ilmu lintasdisipliner ditemukan adanya akar kesamaan pandangan tentang fenomena inklusifitas berupa determinisme resiprokal antara manusia dan budaya (kepingan pertama, disingkat KP1), antara budaya dan bahasa (KP2), dan antara manusia dan bahasa (KP3). Hubungan antarketiga keping ini diwadahi dalam bentuk metaforis "setali tiga keping" (selanjutnya disingkat STK) tentang manusia, budaya, dan bahasa. Titik episentrum pandangan tentang STK yakni manusia berdasarkan kodrat sosialnya menciptakan sistem budaya, sistem sosial, dan artefak yang disebut budaya.Selanjutnya budaya ini dipertahankan, dikembangkan, dan dikomunikasikan secara sinkronis maupun diakronis dengan menggunakan bahasa sebagai alat/medianya.

Diversifikasi kajian antropologi kultural (cultural antrophology) tentang hal di atas paling tidak menghasilkan tesis, yakni akal dan bahasa dalam kehidupan ma-nusia merupakan landasan yang memungkinkan suatu budaya berevolusi. Perkembangan lebih lanjut tesis menghasilkan aksioma berpikir analitis bahwa melalui unsur-unsur bahasa (kata, frasa, kalimat) dalam suatu teks/wacana dapat ditelaah wujud-wujud budaya tertentu.

Kajian psikologi sosial (social psychology) menempatkan bahasa sebagai salah satu system of system yang membentuk interaksi, konteks sosial, dan konteks budaya suatu komunitas. Pernyataan mendasar berkaitan dengan proses rekonstruksi suatu budaya (termasuk melalui data bahasa) didasarkan pada prinsip mendeskripsikan terlebih dahulu elemen emik, kemudian mempergunakannya sebagai dasar menginterpretasikan elemen etik.

Kajian lintas budaya (cross-culture) mempostulasikan bahasa yang berben- tuk lambang/simbol memiliki tiga fungsi strategis dalam konteks komunikasi sosial budaya. Fungsi-fungsi ini meliputi (1) fungsi identitas sosial yakni penandaan identitas masyarakat, misalnya asal-usul suku bangsa, agama, ataupun tingkat/ situasi pendidikan, (2) fungsi integrasi sosial yakni penanaman kesatuan/persatuan antar-kelompok dengan tetap mengakui diversifikasi atribusi masing-masing kelompok, dan (3) fungsi sosialisasi yakni pemerolehan dan pembelajaran nilai-nilai budaya suatu masyarakat baik kepada anggota budaya itu (insider) maupun kepada anggota masyarakat budaya lain (outsider).

Kedua, penelitian ini juga distimulasi oleh semakin meningkatnya fokus dan interes para linguis terhadap komunikasi verbal dalam hubungannya dengan kepercayaan dan perilaku manusia. Berkembangnya sudut pandang konsepsi bahasa dari "seperangkat satuan kalimat yang terbatas/tak terbatas" menjadi "seperangkat lambang bunyi yang memiliki fungsi sosial" menstimulasi munculnya aksioma baru bagi studi bahasa dan budaya dalam bidang kajian linguistik. Konsepsi definitif bahasa tidak hanya berkaitan dengan bentuk dan makna semata, tetapi juga dikaitkan dengan fungsi sosial/kulturalnya. Dalam hal ini Greenberg (1971) mengemukakan bahwa "every language is a cultural subsystem, that such subsystem are distributed over geographical space, and that each meaningful item in a language is a cultural trait that involves 'form' and 'function'. Sejalan dengan hal ini Trager (1949) mengemukakan "language is a system of arbitrary vocal symbols by means of which the members of society interact in terms of their total culture". Sebagai konsekuensi logis dari pandangan ini, maka setiap analisis terhadap data kebahasaan selalu berkaitan dengan aspek di luar bahasa berupa konteks kultural.

Pengembangan fokus studi bahasa di atas kemudian mengilhami munculnya 
linguistik fungsional-sistemik Halliday \& Hasan (1985) yang memandang bahasa sebagai gejala sosial dan dikaji melalui analisis semiotik. Analisis teks/wacana bahasa dalam hal ini dilakukan melalui telaah elaboratif antara konteks situasi dan konteks kultural yang melingkupi proses produksi serta rekognisi suatu teks.

Ketiga, motivasi ideasional peneliti terhadap perkembangan kerangka kerja analisis wacana yakni kajian linguistik dalam penggunaanya (deskriptif dan intepretatif) di satu sisi, dan kajian refleksi social sharing berupa nilai, persepsi, serta orientasi dalam suatu teks/wacana (eksplanatif) pada sisi yang lain. Kajian yang pertama berkembang melalui heterogenetik prosedur analitis antara lain analisis linguistik, strukturalisme Prancis, etnografi komunikasi, filsafat linguistik, pragmatik, analisis varian, dan linguistik fungsional Halidayan. Kajian yang kedua berkembang dalam prosedur analisis linguistik, kewacanaan, dan sosiologikal. Kontroversi keilmuan yang terjadi mendorong peneliti untuk menyusun dan menerapkan suatu komplementasi konstruk model analisis yang memiliki dua kemampuan sekaligus, yakni (1) kemampuan mendeskripsikan (descriptive power atau descriptive adequacy), dan (2) kemampuan mengeksplanasikan (explanatory power atau explanatory adequacy).

Pertanyaan selanjutnya, apakah hubungan timbal balik antara bahasa dan budaya sebagaimana beberapa postulat yang telah dikemukakan juga terdapat dalam bahasa dan budaya Indonesia? Penelitian ini secara umum mengkaji fenomena budaya Indonesia dalam wacana jurnalistik berita berbahasa Indonesia (WJBI).Secara spesifik, terhadap objek penelitian dilakukan eksplorasi secara mendalam tentang orientasi budaya masyarakat Indonesia dalam aspek mikro wacana jurnalistik berita. Aspek mikro meliputi subaspek pola representasi makna, pola gramatikalisasi, dan pola leksikalisasi.

\section{METODE}

Penelitian ini disistematisasi dengan menggunakan pendekatan kualitatif. Jenis penelitian ini adalah analisis wacana interpretatif. Metode yang digunakan, meliputi metode etnografi teks ditinjau dari segi strategi pemahaman budaya Indonesia melalui teks WJ, metode fenomenologi ditinjau dari segi pengumpulan dan representasi data berupa unit-unit bahasa dalam WJ, dan metode hermeneutika-kutural ditinjau dari segi intertekstualitas WJ. Rangkaian kinerja analisis data dikembangkan secara eksistensial dari dua model kajian analisis sebelumnya, yakni analisis wacana deskriptif dan analisis wacana kritis (Silverman, 1995).

Data penelitian ini adalah teks/wacana jurnalistik berita. Wujudnya berupa katakata, kalimat, dan paragraf yang terdapat dalam bagian inti dan badan berita. Sumber data penelitian ini adalah media massa cetak (surat kabar) nasional Kompas dan regional Jawa Pos, masing-masing terbitan bulan Januari, Juni, dan Desember 2007, 2008, dan 2009. Pengumpulan data penelitian ini dilakukan melalui penerapan tiga jenis teknik, yakni observasi terfokus, triangulasi teori dan logis, serta pengambilan bergulir/bola salju. Peneliti bertindak sebagai instrumen kunci, danmenggunakan beberapa instrumen pendamping, meliputi (1) panduan kodifikasi data, (2) panduan kode data, (3) panduan analisis deskriptif, dan (4) panduan analisis interpretatif. Model analisis yang digunakan dalam penelitian ini diadaptasikan dari model analisis mengalir, jenis interaktif dengan tiga tahapan analisis, meliputi (1) pereduksian data, (2) pendisplaian data, dan penarikan inferensi /verifikasi (Miles and Huberman, 1992).

\section{HASIL DAN PEMBAHASAN}

Kajian eksplanatif dan eksploratif terhadap pola representasi makna, gramatikalisasi, dan leksikalisasi dalam teks WJBI telah membuktikan adanya inklusifitas 
orientasi budaya Indonesia. Eksplanasi lebih lanjut berdasarkan praktik diskursif sosiokultural (Hall, 1986; Dijk, 1977, 2003; Fairclough, 1995; Wodak, 1996; dan Fowler, 1996), model-model komunikasi (Cuber, 1947; Brislin, 1981; dan Stark,1987), dan analisis skema kultural Gee (1999) membuktikan bahwa: (a) pola representasi makna dalam teks WJBI mencerminkan kesadaran kolektif tentang bagaimana latar, detail, dan informasi disusun, dimaknai, serta dikomunikasikan, (b) gramatikalisasi dalam teks WJBI mencerminkan kesadaran kolektif tentang bagaimana menghadirkan dan tidak menghadirkan subjek pelaku suatu kejadian/peristiwa, dan (c) leksikalisasi dalam teks WJBI mencerminkan kesadaran kolektif tentang bagaimana situasi, lingkungan, waktu, ruang, dan objek dilambangkan dan dikomunikasikan.

\section{Orientasi Peristiwa}

Berkaitan dengan terjadinya suatu fakta dalam kehidupan sosial dapat dikemukakan bahwa orientasi budaya Indonesia lebih mengarah pada peristiwa daripada waktu. Hal ini ditunjukkan melalui bentukan-bentukan obligat yang merefleksikan dua indikator, yakni (a) penjadwalan yang tidak ketat dengan ciri toleransi waktu yang bersifat longgar dan (b) peristiwaperistiwa dibiarkan berlangsung sampai selesai tanpa memperdulikan waktu. Lima bentukan obligat dalam aspek mikro WJBI yang merefleksikan indikator tersebut, meliputi (a) bentukan keduniaan, (b) bentukan aktivitas, (c) bentukan identitas dan relasi sosial, (d) bentukan politik, dan (f) bentukan hubungan.

\section{Orientasi Pemikiran Holistik}

Berkaitan dengan cara pandang terhadap suatu fakta sosial dapat dikemukakan bahwa orientasi budaya Indonesia lebih mengarah pada pemikiran holistik daripada dikotomis. Hal ini ditunjukkan melalui bentukan-bentukan obligat yang merefleksikan dua indikator, yakni (a) memperhatikan sesuatu hal secara utuh dan menyeluruh dan (b) melakukan sintesis tetapi tidak memberikan perhatian yang terlalu besar pada harmonisasi analitis atau detail-detail. Enam bentukan obligat dalam aspek mikro WJBI yang merefleksikan gejala itu, meliputi (a) bentukan semiotik, (b) bentukan keduniaan, (b) bentukan aktivitas, (c) bentukan identitas dan relasi sosial, (d) bentukan politik, dan (f) bentukan hubungan.

\section{Orientasi Non-Kritis}

Berkaitan dengan cara pandang dalam merencanakan, melaksanakan, dan menilai hidup serta kehidupan dapat dikemukakan bahwa orientasi budaya Indonesia lebih mengarah pada pemikiran nonkritis daripada kritis. Hal ini ditunjukkan melalui bentukan-bentukan obligat yang merefleksikan dua indikator, yakni (a) selalu menerima hidup apa adanya dengan cara memilih dari beragam alternatif cara hidup dan (b) hanya bertindak jika suatu krisis terjadi. Lima bentukan obligat dalam aspek mikro WJBI yang merefleksikan gejala itu, meliputi (a) bentukan semiotik, (b) bentukan keduniaan, (c) bentukan aktivitas, (d) bentukan identitas dan relasi sosial, dan (f) bentukan hubungan.

\section{Orientasi Hubungan Manusia}

Berkaitan dengan penyelesaian suatu aktivitas dapat dikemukakan bahwa orientasi budaya Indonesia lebih mengarah pada hubungan manusia daripada daripada tugas itu sendiri. Hal ini ditunjukkan melalui bentukan-bentukan obligat yang merefleksikan dua indikator, yakni (a) mengandalkan hubungan baik dan persahabatan dalam beraktivitas dan (b) permertahanan relasi daripada tujuan ataupun prestasi menyelesaikan suatu aktivitas. Tiga bentukan obligat dalam aspek mikro WJBI yang merefleksikan gejala itu, meliputi (a) bentukan aktivitas, (b) bentukan identitas dan relasi sosial, dan (c) bentukan hubungan. 


\section{Orientasi Pada Status}

Berkaitan dengan apresiasi terhadap individu/kelompok dapat dikemukakan bahwa orientasi budaya Indonesia lebih mengarah pada status daripada prestasi. Hal ini ditunjukkan melalui bentukanbentukan obligat yang merefleksikan gejala lebih menghargai status, kedudukan, peran sosial tertentu daripada prestasi dan kemampuan individu/kelompok. Empat bentukan obligat dalam aspek mikro WJBI yang merefleksikan gejala itu, meliputi (a) bentukan keduniaan, (b) bentukan aktivitas, (c) bentukan identitas dan relasi sosial, dan (d) bentukan hubungan.

\section{Orientasi Kerentanan Disembunyikan}

Berkaitan dengan proses dan hasil aktivitas individu/kelompok dapat dikemukakan bahwa orientasi budaya Indonesia lebih mengarah pada penyembunyian kerentanan daripada memperlihatkan kerentanan. Hal ini ditunjukkan melalui bentukan-bentukan obligat yang merefleksikan kesadaran kolektif berbentuk pedoman bahwa kesalahan, kegagalan, dan kelemahan seharusnya tidak dibeberkan atau diungkapkan untuk umum. Lima bentukan obligat dalam aspek mikro WJBI yang merefleksikan gejala itu, meliputi (a) bentukan semiotik, (b) bentukan keduniaan, (c) bentukan aktivitas, (d) bentukan identitas dan relasi sosial, dan (e) bentukan hubungan.

\section{SIMPULAN}

Hasil penelitian menunjukkan bahwa orientasi budaya Indonesia yang ditemukan dalam aspek mikro subaspek pola representasi makna, gramatikalisasi, dan leksikalisasi mengarah pada tipologi budaya kolektivis (collectivist culture). Aktivitas masyarakat Indonesia dalam berbagai fakta sosial menunjukkan kesesuaian dengan indikator-indikator posisi kesadaran budaya kolektivistik sebagaimana dicantumkan dalam panduan analisis interpretatif. Enam orientasi budaya Indonesia yang ditemukan, adalah: (a) berorientasi pada peristiwa dengan ciri penjadulan yang bersifat longgar dan membiarkan suatu peristiwa berlangsung tanpa memperdulikan waktu, (b) berorientasi pada pemikiran holistik dengan ciri melihat sesuatu secara utuh tanpa memberikan perhatian terlalu besar terhadap harmonisasi detail, (c) berorientasi non-kritis dengan selalu menerima hidup apa adanya dan bertindak jika suatu krisis telah terjadi, (d) berorentasi pada hubungan manusia dengan ciri mempertahankan relasi dalam pelaksanaan tugas, (e) berorientasi pada status dengan ciri menghargai status, kedudukan, dan peran sosial tertentu daripada prestasi dan kemampuan, dan (f) berorientasi pada kerentanan disembunyikan dengan pedoman tidak mengungkapkan suatu kesalahan, kegagalan, dan kelemahan secara terbuka dan publikatif.

Berkaitan dengan hal di atas, saransaran pemanfaatan dan pengembangan lebih lanjut penelitian dan temuan penelitian dikemukakan kepada pihak-pihak berikut. Para guru bahasa Indonesia di pendidikan dasar ataupun menengah dan dosen bahasa Indonesia di perguruan Tinggi disarankan untuk mencermati hasil penelitian ini sebagai bahan pertimbangan pengembangan orientasi pembelajaran bahasa khususnya wacana BI. Pengembangan orientasi yang dimaksudkan adalah ekstensifikasi arah dan tujuan pembelajaran wacana BI. Perencanaan, pelaksanaan, dan pengevaluasian pembelajaran wacana BI diarahkan pada dua pengalaman kesadaran, yakni (a) kesadaran berbahasa komunikatif (communicative language awareness), dan (b) kesadaran berbudaya kritis (critical culture awareness).

Para penulis buku ajar bahasa Indonesia: model analisis deskriptif dan interpretif dalam penelitian ini dapat dijadikan sebagai acuan pengembangan langkah-langkah kegiatan siswa. Kompleksitas tahapan analisis disesuaikan dengan sasaran penyusunan buku ajar, meli- 
puti jenjang pendidikan, kompetensi, dan alokasi waktu pembelajaran. Para penyusun kurikulum sekolah/silabus bahasa Indonesia: pengembangan silabus bahasa Indonesia selain berorientasi pada pembentukan kompetensi (pengetahuan) bahasa dan performansi (keterampilan) berbahasa, hendaknya berorientasi pula pada pembentukan kepribadian dan kemanusiaan siswa. Hal ini dapat ditempuh dengan cara-cara, antara lain (a) materi pokok kewacanaan bersumber pada masalah-masalah yang berkembang dalam masyarakat, kebutuhan masyarakat, dan berbagai sistem budaya, sosial, serta artefak yang dimiliki masyarakat, (b) memposisikan siswa sebagai subjek belajar dengan berbagai pengalaman belajar individual dan kelompok, dan (c) menjadikan lingkungan budaya mayoritas masyarakat dan pribadi siswa sebagai entry behavior kultural siswa.

Para praktisi jurnalistik berita berbahasa Indonesia: hendaknya melihat perspektif fungsi mendidik dan kontrol sosial tidak hanya dari sisi fokus pemberitaan semata, tetapi juga dari sisi efek penggunaan (memilih dan memfungsikan) bahasa. Sebagaimana telah dideskripsikan dalam penelitian ini bahwa fitur-fitur kebahasaan wacana berita jurnalistik dapat merefleksikan berbagai sistem budaya, sosial, dan artefak. Dengan kata lain wujud-wujud budaya dengan berbagai elemen tersebut terinstitusionaliasi selama proses produksi berita, sehingga pada tataran resepsi berita wujud-wujud ini akan terinternalisasi dalam pikiran kognitif pembaca.

Para peneliti dan pemerhati bahasa Indonesia: Medan gagasan berkaitan dengan substansi penelitian ini masih sangat tebuka untuk dikembangkan lebih lanjut. Oleh sebab itu disarankan kepada para peneliti lain dan pemerhati bahasa Indonesia untuk mengembangkan penelitian sejenis dalam berbagai orientasi dan perspektif. Orientasi yang dimaksudkan berkaitan dengan diversifikasi objek kewacanaan bahasa Indonesia sebagai sasaran kajian. Perspektif yang dimaksudkan adalah divergensi bidang keilmuan yang dirujuk sebagai penguat konstelasi kerangka berpikir dalam melaksanakan penelitian. Pernyataan dasar yang menyertai saransaran ini bahwa dedikasi dan loyalitas dalam menyeimbangkan kesadaran berbahasa dan kesadaran berbudaya Indonesia merupakan prasyarat menuju bahasa Indonesia yang modern, cendekia, dan dinamis sebagai identitas bangsa.

\section{UCAPAN TERIMA KASIH}

Ucapan terimakasih disampaikan kepada teman sejawat yang telah berkenan menjadi mitra diskusi dalam pemahaman permasalahan dalam artikel ini. Selanjutnya ucapan terimaksih diucapkan kepada reviewer yang telah membaca, mengoreksi dan memberi masukan terhadap artikel ini.

\section{DAFTAR PUSTAKA}

Brislin, Richard W. 1981. Cross-Cultural Encounters: Face to Face Interaction. New York: Pergamon Press.

Chaika, E. 1982.Language The Social Mirror. Newsbury: Newsbury House Publishers.

Clark, H.E. and Clark, E.V. 1977. Psychology and Language: An Introduction to Psycholinguistics. New York: Harcourth Brace Jovanovich Inc.

Cuber, John F. 1947. Sociology: A Synopsis of Principles. New York: D. AppletonCentury Company.

DuFon, Margaret A. \& Wahab, Abdul. 1994. A Cross-Linguistic Comparasion of the Semantic Fields for Politeness in English, Javanese, and Indonesian. Jurnal Pendidikan Humaniora dan Sains 1(1): 121-143.

Eriyanto.2001. Analisis Wacana: Pengantar Analisis Teks Media. Yogyakarta: LKiS.

Fairclough, N. 1995. Critical Discourse Analysis: The Critical Study of Language. London: Longman. 
Fowler, Roger. 1996. Linguistic Critisim. Oxford: Oxford University Press.

Gee, J.P. 1999. Discourse Analysis. London: Clays Ltd.

Geertz, C. 1973. The Interpretation of Cultures. New York: Basic Books, Inc.

Giglioli, P.P. (Ed). 1985. Language and Social Context. Harmondsworth: Penguin Books Ltd.

Gumperz, J.J. 1968. “The Speech Community". Dalam Paolo Giglioli (Ed.). 1985. Language and Social Context (hlm. 219-231). Harsmondsworth: Penguin Books. Ltd.

Gunarwan, Asim. 1992. Persepsi Kesantunan Direktif di dalam Bahasa Indonesia di Antara Beberapa Kelompok Etnik di Jakarta. Dalam Bambang Kaswanti Purwo (Penyunting). PELLBA 5 (hlm. 179215). Yogyakarta: Penerbit Kanisius.

Greenberg, J.H. 1971. Language Universal. The Hague: Mouton Publisher.

Hall, S. 1986. "Encoding/Decoding", Dalam Stuart Hall, Dorothy Hobson, Andrew Lowe, dan Paul Willis (Eds.).Culture, Media, and Language (hlm.136-138). London: Hutchinson.

Halliday, M.A.K and Hasan, R. 1985. Language, Context, and Text: Aspek of Language in A Social-Semiotic Perspective. Oxford: Oxford University Press.

Hayakawa, S.I. and Hayakawa, A.R. 1990. Language in Thought and Action. San Diego: Harcourt Brace Jovanovich Inc.

James Fox, Wertsch. 1986. Vigotsky and The Social Formation of Mind. USA: Harvard University Press.

Kartomihardjo, S. 1981. Ethnography of Communicative Codes in East Java. Canberra: Departement of Linguistics Research School of Pacific Studies, The Australian National University.

Martinich, A.P. 2001. The Philosophy of Language. Oxford: Oxford University Press.

Miles, M.B. and Huberman, A.M. 1992. Analisis Data Kualitatif. Terjemahan Tjejep Rohendi Rohidi. Jakarta: Universitas Indonesia.
Nababan, P.W.J. 1984. Sosiolinguistik. Jakarta: PT Gramedia.

Noerhadi, T.H. 1992. "Bahasa sebagai Penggambaran Dunia". Dalam Bambang Kaswanti Purwo (Ed).

Purwo, Bambang Kaswanti (Ed.). 1992. PELLBA 5: Bahasa Budaya. Yogyakarta: Penerbit Kanisius.

Santoso, A. 1995." Penalaran sebagai Transaksi Kritis".Jurnal Pendidikan Humaniora E Sains. 1(2): 56-64.

Silverman, D. 1995. Interpreting Qualitative Data: Methods for Analizing Talk, Text, and Interaction. California: SAGE Publication.

Stark, Rodney. 1987. Sociology. California: Wadsworth Publihsing Company.

Suparti, S.M. (dkk.). 1992. "Leksikon dan Taksonomi Emosi". Dalam Bambang Kaswanti Purwo (Penyunting). PELLBA 5 (hlm. 97-122). Yogyakarta: Penerbit Kanisius.

Trager, G.L. 1949. "Paralanguage: a First Approzimation". Studies in Linguistics. 13(1):1-2.

Valdes, Joyce Merrill. 1995. Culture Bound. Cambridge: Cambridge University Press.

Van Dijk, T.A. 1977. Text and Context Explorations In The Semantics and Pragmatics of Discourse. New York: Longman.

Van Dijk, T.A. 2003."Critical Discourse Analysis". Dalam Deborah Schiffrin (Eds) The Handbook of Discourse Analysis (hlm. 352-371). Malden: Blackwell Publishing.

Wahab, A. 1998.Isu Linguistik Pengajaran Bahasa dan Sastra. Surabaya: Airlangga Univesity Press.

Wertsch, J.V. 1985. Vigotsky and The Social Formation of Mind. Cambridge: Harvard University Press.

Wodak, Ruth \& Reisigl, Martin. 1996. Discourse and Racism. Dalam Deborah Schiffrin (Eds.), The Handbook of Discourse Analysis (hlm. 372-397). Malden: Blackwell Publishing. 